\title{
REDIMAT
}

Journal of Research in Mathematics Education

Instructions for authors, subscriptions and further details:

http://redimat.hipatiapress.com

\section{Using a New Schema Approach with Primary at Risk Students in Word Problem Solving}

Parvaneh Amiripour ${ }^{1}$, John Arthur Dossey ${ }^{2}$ and Ahmad Shahvarani ${ }^{1}$

1) Islamic Azad University

2) Illinois State University

Date of publication: October $24^{\text {th }}, 2017$

Edition period: October 2017-February 2018

To cite this article: Amiripour, P, Dossey, J.A., \& Shahvarani, A. (2017). Using a new schema approach with primary at-risk students in word problem solving. REDIMAT, 6(3), 228-255. doi: 10.1783/redimat.2017.2612

To link this article: http://dx.doi.org/10.17583/redimat.2017.2612

\section{PLEASE SCROLL DOWN FOR ARTICLE}

The terms and conditions of use are related to the Open Journal System and to Creative Commons Attribution License (CC-BY). 


\section{Using a New Schema Approach with Primary At-Risk Students in Word Problem Solving}

Parvaneh Amiripour Islamic Azad University
John A. Dossey

Illinois State

University
Ahmad Shahvarani

Islamic Azad

University

(Received: 03 March 2017; Accepted: 06 October 2017; Published: 24 October 2017)

\section{Abstract}

This comparative study of two approaches contrasts a schema-based approach to represent a solution approach to solving whole number contextual problems for grades 2 and 3 with the traditional textbook approach. The participants are 9 to 11year-old Afghani refugee students enrolled in non-public schools administered by NGO organization in Iran. The subjects have difficulty with grade-level mathematics and have been retained in grade at least one year. Subjects were randomly selected from four classrooms in two schools. The schema-based experimental approach is called the Problem Patterns (PP) approach. Students receiving this instructional approach were taught to break problems into data, units, and desired solution, removing irrelevant information, and make a solution model with manipulatives. Control students followed the traditional classroom approach. All classes were taught by the first researcher. Evaluation results showed the PP students had higher achievement and growth scores than the control students. The results also showed the schema building portion of instruction contributed most to the differences in performance of the experimental groups' students.

Keywords: Mathematical learning, problem pattern approach, schema-based problem solving, word problems, at-risk students 


\section{Uso de un Nuevo Enfoque} Esquemático de Resolución de Problemas con Palabras con Estudiantes de Primaria en Riesgo

Parvaneh Amiripour Islamic Azad University
John A. Dossey

Illinois State

University
Ahmad Shahvarani

Islamic Azad

University

(Recibido: 03 Marzo 2017; Aceptado: 06 Octubre 2017; Publicado: 24 Octubre 2017)

\section{Resumen}

En este estudio se comparan dos enfoques, uno basado en esquemas para representar una forma de solución para resolver problemas contextuales con números enteros para los grados 2 y 3 , con otro basado en el enfoque tradicional del libro de texto. Los participantes son estudiantes refugiados afganos de 9 a 11 años inscritos en escuelas no públicas administradas por una organización no gubernamental en Irán. Los sujetos fueron seleccionados al azar de cuatro clases en dos escuelas. Los estudiantes en el grupo de control siguieron el enfoque tradicional de la clase. Todas las clases fueron impartidas por el primer investigador. Los resultados de evaluación muestran que los alumnos que usaron el enfoque PP tuvieron un mejor rendimiento que los alumnos en el grupo de control. Los resultados también muestran que la porción de formación de esquemas de la enseñanza fue lo que más contribuyó a las diferencias en rendimiento de los estudiantes en el grupo experimental.

Palabras clave: Estudiantes en riesgo, aprendizaje matemático, enfoque de patrones de problemas, resolución de problemas basada en esquemas 


\section{Amiripour, Dossey \& Shahvarani - New Schema Approach}

tudies of elementary students' achievement and progress in mathematics highlights the important role played by the ability to establish and develop the fundamental skills in solving numerical problems delivered in context (National Mathematics Advisory Panel, 2008). This study focuses on a new approach to teaching and assessing instruction for at-risk second and third grade students' in mastering such skills and procedures. With numeracy skills needed more than ever in the work place, today's students must be able to compute fluently, engage in logical reasoning and use mathematics to tackle novel problems. However, PISA 2012 results show that only a minority of 15-year-old students in most countries grasp and can work with core mathematics concepts...'Opportunity to learn' refers to the content taught in the classroom and the time a student spends learning this content. Not all students, not even those in the same school, experience equal opportunities to learn. Reducing inequalities in access to mathematics is not an impossible task. PISA results show that performance disparities between socio-economically advantaged and disadvantaged students are largely linked to differences in students' familiarity with mathematics. Thus, raising disadvantaged students' opportunities to learn mathematics concepts and processes may help reduce inequalities and improve the average level of performance" (OECD, 2016, p. 13).

McCann \& Austin (1988) described three features of an at-risk student:

- Learner in severe danger of not attaining the ends of education exhibited through failure to reach local or state standards for high school graduation and/or failure to gain the understandings, skills, and dispositions to become an industrious participant of society.

- Learner who displays actions that instructors categorize as interfering with the learning and educational processes

- Learner whose domestic or community upbringing and/or experience may place him or her at-risk. Conventionally, educationalists have examined the economic status of students and used it as an initial indication in efforts to determine if a student is at-risk of not succeeding in school. (p. 4) 


\section{Mathematics Difficulties at the Elementary Level}

Mathematics difficulties (MD) at the elementary level, in addition to the growth of at-risk factors, lead to long-term difficulties in learning. "In the absence of effective interventions, many students who enter first grade with mathematics delays stay behind throughout their school careers" (Morgan et al., 2009, p. 311). When these children enter school with difficulties, they are unable to experience the same progress and success as their counterparts. This, in turn, leads to a pattern of unpreparedness for mathematics instruction in the following elementary grades (Jordan, 2007; Jordan et al., 2006; National Mathematics Advisory Panel, 2008; National Research Council, 2009; Starkey et al., 2004). These reports indicate that "low-income children comprise $76 \%$ of fourth graders who scored in the lowest $25 \%$ for mathematics, an increase of $2 \%$ from earlier reports." These, and other, results suggest that the use of effective and systematic intervention for MDs is so important for at-risk children with difficulties in culture, social, and educational venues. Assessments of number competencies and skills are a major estimate of the degree of mathematics achievement these students will experience (Jordan et al., 2009, p. 862). The level of mathematics achievement of kindergarten children is constantly found to be a major predictor of mathematics achievement in later grades (Claessens et al., 2009; Duncan et al., 2007; Duncan \& Magnuson, 2011). "Understanding of number concepts and relations helps children perform arithmetic operations and can be applied to other mathematical domains such as measurement, data analysis, and geometry" (National Research Council, 2009, p. 332). Children, who have difficulties with number competencies and rote memorization, will have difficulties in skills for PS, arithmetic and computation (Robinson et al., 2002). The Common Core State Standards in Mathematics (CCSSM) reported that "by the end of kindergarten, children should be able to count to 100 by ones and tens, write numbers from 0 to 20 , understand one-to-one correspondence and cardinality, compare numbers, solve addition and subtraction problems with objects, solve word problems (WP), and fluently add and subtract within five, among other skills" (National Governors Association Center for Best Practices \& Council of Chief State School Officers, 2010, p. 332).

Practices that are based in understanding contribute to learners' 


\section{Amiripour, Dossey \& Shahvarani - New Schema Approach}

knowledge through 'long-term representations' of combinations. An early focus on conceptual understanding and representations of such knowledge forms a basis that is accessible for application in future contexts (Fuchs et al., 2013; Jordan, 2007).

\section{Knowledge About Word Problems}

Studies focusing on elementary students reading of the words of text in a WP, show that many of them have difficulties in identifying the main information and linking it to a number sentence representing the relationships at the core of the problem. Other studies have found that a schematic approach to problem solving can assist in developing the capacity of WPs. Learner/s who solve problems efficiently, are often able to find the 'superficial surface features' of a WP and can then determine the main structure or 'schema of the problem'. When they subsequently learn that a WP often might have different story forms, they are then able to draw out several mathematical relationships in detail (Powell, 2011). In comparison, learners who are weak solvers are more likely distracted by "irrelevant information" such as keywords. These students are usually unable to determine or verbally report the similarities/differences in words between the structures of the sentences. This may result from the fact that in their mind such structures do not relate to the main goals of WPs (Schiff et al., 2009). Carpenter \& Moser (1983) categorized WPs into three main schemas: 'Change, Difference and Combine'. Other studies found that when numbers above 10 (two digits) were written in a WP, many students were not capable of identifying the main schema of the WP. Also, unknown amounts/numbers appearing in a WP leads to mistakes when students need to interpret them in a WP (Garcia et al., 2006). In one-step problems, the status and understanding of the "unknown numbers" occurs in three forms:

- Result is unknown $(5-2=$ ?),

- Change is unknown $(5-?=3)$, and

- Start is unknown $(?-2=3)$.

Findings in these studies report that students can often work their way through modeling the first two models, they experience extreme difficulty in wrestling with the "Start is unknown" problems (Garcia, et al., 2006, p. 278). The most difficult format is the 'unknown start' in that it triggers mistakes or use of mistaken methods. It is possible that many students 
attempt to reword/rework WP into this style: ? $-2=3 \rightarrow 3+2=5$. It seems that maybe some students are unable to find form, or format, to apply when they face such WP contexts. To develop real efficiency with at-risk students with WPs, it appears that we may have to follow another teaching method for WPs (Kroesbergen et al., 2003). There are many direct approaches for teaching students WPs to at-risk students (Jitendra \& Xin, 1997). These direct approaches to WPs include:

- Diagramming WPs (Van Garderen, 2007),

- Identifying keywords and solving with emphasis on the keywords,

- Using computer-assisted instruction with direct step-by-step strategies (Mastropieri et al., 1997),

- Using 'mnemonic tools' to guide WPs (Miller \& Mercer, 1993),

- Teaching meta-cognitive approaches to control WPs process (Case et al., 1992);

- Using a checklist of steps to solve WPs along with supervising using meta-cognitive approaches (Montague \& Applegate, 2000).

A progressive approach to helping at-risk students learn how to solve WPs, which has been improved over the last 30 years, is the use of a 'schematic diagram' to solve WPs (e.g., Fuchs et al., 2004; Jitendra \& Hoff, 1996). "WP instruction using schemas differs from typical WP instruction (e.g., key words, checklist of steps) because students first identify a WP as belonging to a problem type and then use a specific problem-type schema to solve the problem" (p. 3). In routine WP teaching, students may identify WP information or/and follow a mnemonic tool to work step-by-step during WPs. It seems that students, and especially at-risk students require many teaching approaches when they solve WPs. One of these approaches is the use of schema embedded in concrete models. Such an approach, which we call the Problem Pattern (PP) approach, is at the core of our study.

\section{Method}

\section{Participants}

Two grades 2 and two grades 3 classes were purposeful selected from each of the four participating schools administrated by the non-governmental organizations: Society for Protecting the Rights of the Child and the 


\section{Amiripour, Dossey \& Shahvarani - New Schema Approach}

Association of Protection of Children Labor. Such societies in Iran focus on at-risk children in education, health care, consultative services for families, and life skills training for children injured in war and natural disasters. In the present study, all the students selected were at-risk Afghani students living in the southern sectors of Tehran. Further, these students laboured a portion of each day as sellers in the markets or in performing menial labour.

Participants from the classes were then purposefully selected using the criteria of having a record of mathematical difficulties and having been retained in grade at least once so far in their schooling. These students' classrooms were then randomly assigned to be either in a control or experimental classroom.

\section{Instruments}

The researcher sought and created a variety of measures of aspects of number and operation items to use in assessing student learning of WPs learning throughout study. The instruments included pretests and posttests, and four interim tests given at two-week intervals throughout study, including the beginning and end of the study. Each test consisted of tenword problems (WPs) attuned to the lessons so that they contained the same variety of difficulty levels of problems for each grade: easy (2 questions), difficult (4 questions), and very difficult (4 questions). In the pretests, some of the WPs had irrelevant information added, while other problems included cases that required students to carefully relate the information involved to develop a final solution to the problem. Some of WPs required more than one operation. In the second grade, WPs required two operators: addition or subtraction. However, WPs for third graders required up to four main operations: addition, subtraction, multiplication, or division. For pretests and posttests, ten WPs were developed following the same difficulty structure. Some of the WPs had added information and some required more than one operation for solving them. Each test had a total possible score of 20 points (See Table 1). These tests were examined by teachers in the schools and by university mathematics educators. Both groups agreed that the items were appropriate for the grade levels and appropriately classified with respect to difficulty. Thus, the tests were accepted as valid measures of student achievement. With respect to the reliability of the mathematical tests developed for pretests, interim tests, 
and posttests by grade levels, developmental work focused on creating tests equivalent to those used in similar work with students at the impacted grade levels. Table 1 displays the timing of the tests and the resulting reliability coefficients computed with Cronbach's $\alpha$. These values were between 0.85 and 0.90 for the pretest, the four interim tests, and posttest at grade 2 and between 0.82 and 0.89 for the tests at grade 3 . The results suggest that use of these instruments in classes was appropriate.

Table 1.

Examination time line and test reliabilities (Cronbach, 1951)

\begin{tabular}{llll}
\hline $\begin{array}{l}\text { Final math exam } \\
\text { Before teaching }\end{array}$ & $\begin{array}{l}\text { 20 days before pretests } \\
\text { Pretest (8 days before } \\
\left.1^{\text {st }}\right)\end{array}$ & $\begin{array}{l}\alpha=0.80 * \\
\alpha=0.86 *\end{array}$ & $\begin{array}{l}\alpha=0.81 * * \\
\alpha=0.83 * *\end{array}$ \\
$\begin{array}{l}1^{\text {st }} \text { week } \\
2^{\text {nd }} \text { week } \\
3^{\text {rd }} \text { week } \\
4^{\text {th }} \text { week }\end{array}$ & First session exam & $\alpha=0.87 *$ & $\alpha=0.85 * *$ \\
$5^{\text {th }}$ week & & & \\
$6^{\text {th }}$ week & Second session exam & $\alpha=0.87 *$ & $\alpha=0.84 * *$ \\
$7^{\text {th }}$ week & & & \\
$8^{\text {th }}$ week & & $\alpha=0.85 *$ & $\alpha=0.82 * *$ \\
$9^{\text {th }}$ week & Third session exam & \\
$10^{\text {th }}$ week & & & \\
$11^{\text {th }}$ week & & $\alpha=0.87 *$ & $\alpha=0.84$ \\
$12^{\text {th }}$ week & Fourth session exam & $\alpha=0.89 *$ \\
After $12^{\text {th }}$ week & Posttest $(10$ days after & $\alpha=0.90 *$ & $\alpha$ \\
& $12^{\text {th }}$ week) & & \\
\hline
\end{tabular}

* Reliability for grade 2

** Reliability for grade 3

Note: Final math exam is implemented through both associations before pretests

\section{Instruction by New Schema Approach}

As all students in the study, whether in the control or experimental sections, were taught by the researcher, so that any variance due to teacher effects 


\section{Amiripour, Dossey \& Shahvarani - New Schema Approach}

was lessened to the degree possible. Further, many of the students were repeating their current grade, so they were repeating the traditional method of instruction from the Iranian grade text book for a second year. The only variation in instruction by the researcher was that when the content of the word problem solving (WPs) portion of the curriculum was covered the experimental sections, the problem pattern approach (PP) to solving WPs was taught in grades 2 and 3. When the traditional approach for teaching WPs was taught in the control sections, the researcher followed the approach used in the Iranian textbook for each of the respective grades.

Neither the researcher nor the student's regular classroom teachers were graduates of a teacher education program. Thus, all were acting from their experience in teaching mathematics based on general experience in teaching, not knowledge of specific teaching approaches tied to the materials with grade 2 and grade 3 students. Further, the problems on the instruments described below were new to all the students.

\section{Linear PPs}

The researcher used a simple PP format as a pilot step for experimental group students. Such a PP structure is found in the form of three main WPs. Consider the following problems that were developed by Jitendra (2002), along with a schema for solving each problem.

Problem: A balloon man had some balloons. Then 14 balloons blew away and the man now has 29 balloons. How many balloons did the man begin with? (Jitendra, 2002).

The following steps illustrate the nature of moving through a word problem using the PP approach (refer to Figure 1). First, a student reads a problem at a level of generality, then moves to find numbers and words that are clear in the WP. Then student draws several circles. These circles serve as the receptacles for writing in the main data points in numbers and words. At the second step, the student must determine and draw an operator's circle with another color. That is, the color of the data points' circles should differ from that of an operator's circle. This second circle is added to the PP model. At this point, the student must find a suitable path among the data's circles and operator's circle to represent the problem. These different color representations among the circles should be based on logical relationships among the numbers, words, and the operator(s). In this step, students must 
draw connecting lines among circles with another color. As a third step, the student observes a main way of drawing a PP for the WP. This main way indicates 'unknown and known information'.

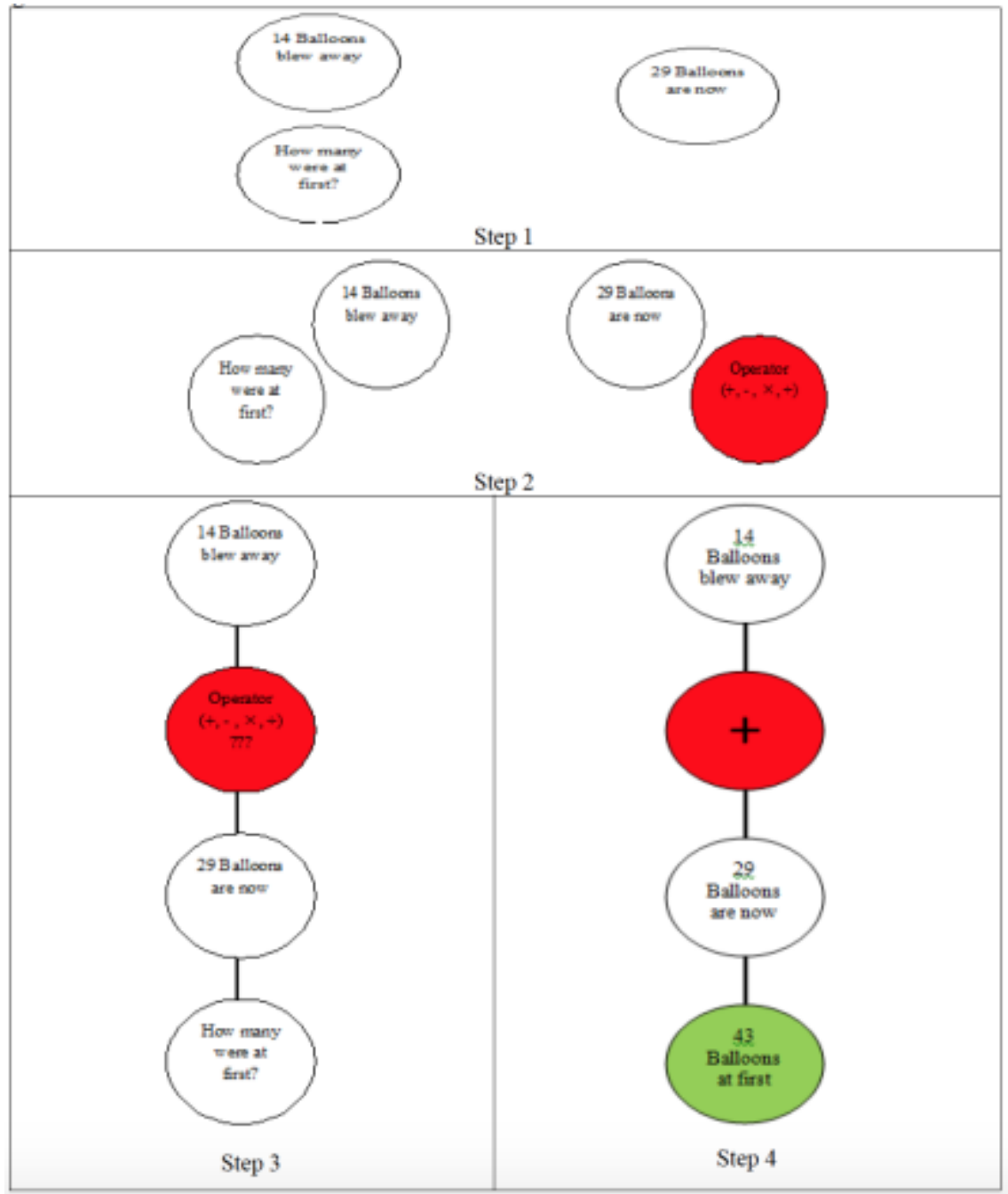

Figure 1. The steps of drawing a linear PP for the change problem 
The student can discover that an addition operator is needed by assistance from the teacher the first time through the problem. But, then he/she should select the operator later by herself or himself. In the fourth step, it is obvious that student must add the two main numerical pieces of data information to access the final answer. 'Addition operator' can show numbers of balloons at start (see Figure 1). It is essential that the answer and operator's circle differ from the color of the other data circle.

In constructing a PP approach model, one may have an information circle/s that has no relationship to other circles. Such information with no relationship to the other information is irrelevant to a solution. The Figure 2 below is such a problem.

Problem: Barbara is 37 years old. Cindy is 7 years older than Barbara. Anne is 8 years old too. How old is Cindy?

In this problem, the age of Anne is irrelevant information, as the PP model shows clearly this circle has no relationship to other circles. Anne's age circle is not connected to any of the other circles.

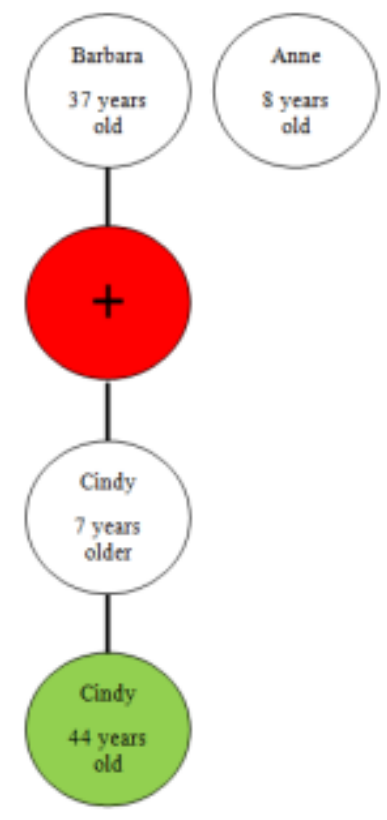

Figure 2. A linear PP problem with irrelevant information 


\section{Nonlinear PPs}

Many WPs situations have more than one operator, but their connection of circles differs from that found in linear PPs. They differ in the fact that their solution cannot be represented as a linear path or segment. When a student reads a nonlinear WP, he/she notes that the structure of that problem requires two or more operators. The difficulty resides in finding the connection/s among the main information (numbers and words) and operators. When the student recognizes there appears to be too many circles representing information circles and operator circles, they have their first clue that the situation may call for a nonlinear PP model. In linear PPs, lines have same color, but not so for nonlinear PPs. If the student tries to make a PP with lines of the same color, the student will not be able to find a main path involving its operator circles. Thus, students must determine ways using connecting lines with different colors. This makes the main path among circles and lines more easily determined. Through using different colored lines, students find how to follow and merge a collection of paths for accessing a main path for the solution. Among nonlinear PP problems, it is observed that: (a) Each sub-path has one operator, (b) Irrelevant information does not fit into any paths or operator, (c) Each sub-path has a unique color, (d) Two operators or more cannot be in a single path, and (e) Nonlinear PPs are unique; that is, a PP that can be slid or rotated onto the shape of a correct PP which is also a correct solution. Consider the following problem.

Problem: Mary has $\$ 1000$. She wants to buy 2 red apples which are $\$ 50$ apiece and 4 cucumbers which are $\$ 50$ apiece. How many dollars did she spend? How many dollars has she now?

Considering the problem, a student finds numbers and words that have a relationship to the context. Write numbers/words in circles as shown in the first step. For the second step, the student must find the total price of 2 red apples and 4 cucumbers. From previous experiences, a student knows that 'multiplication' is the operator. Returning to previous knowledge regarding linear PPs, a student can find the price of both 2 red apples and 4 cucumbers separately (see Figure 3). For the third step, the student is required to read through the problem again. The main question is to what remains from Mary's original amount of money. Thus, student must first 
238 Amiripour, Dossey \& Shahvarani - New Schema Approach

add to find the total price of red apples and cucumbers altogether and then subtract this sum from the original money amount to find the remainder of Mary's money. A circle containing $\$ 300$ has been computed from the addition of circles of $\$ 100$ and $\$ 200$ in the two linear PPs represented by sub-paths.

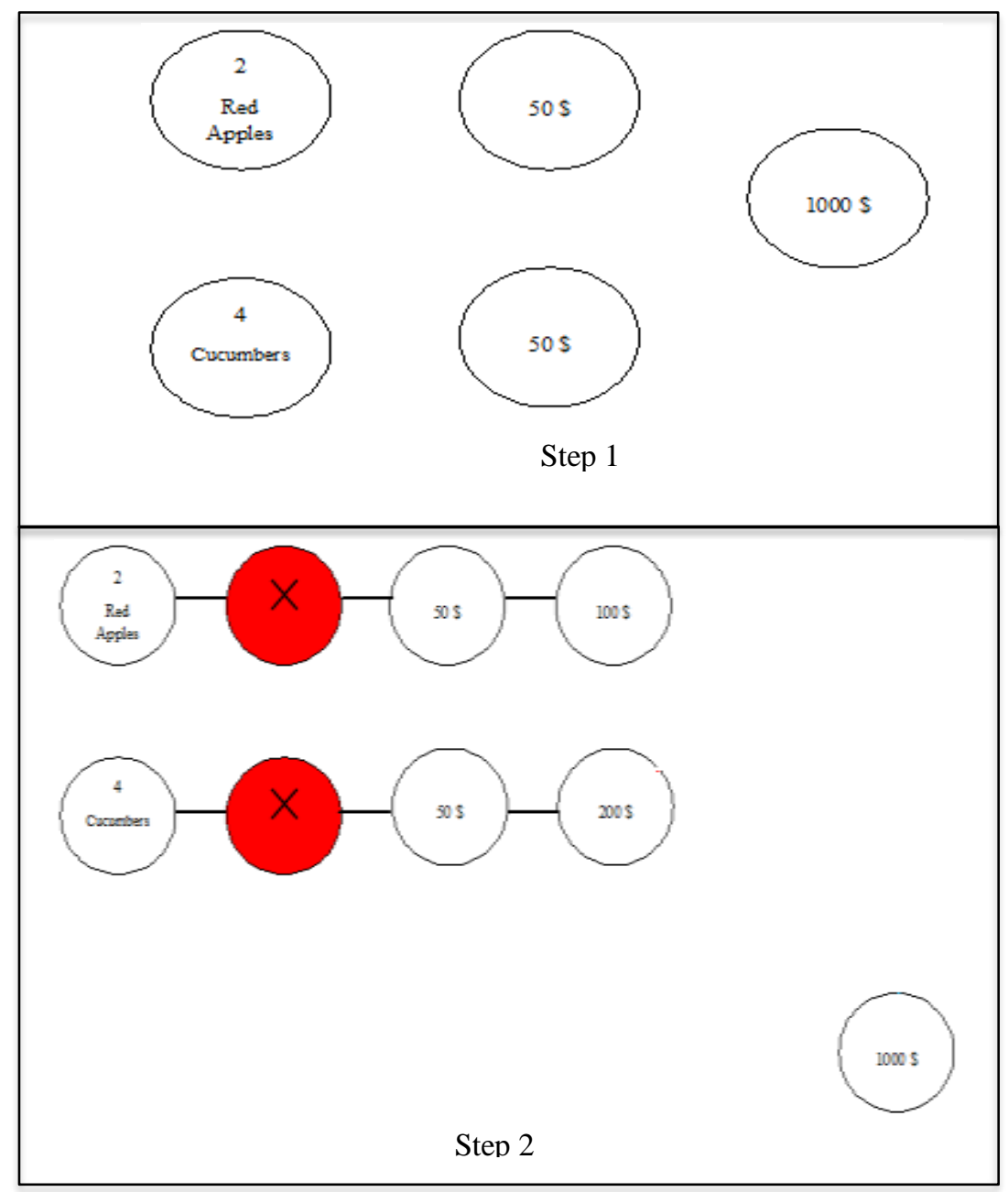

Figure 3. A nonlinear PP 


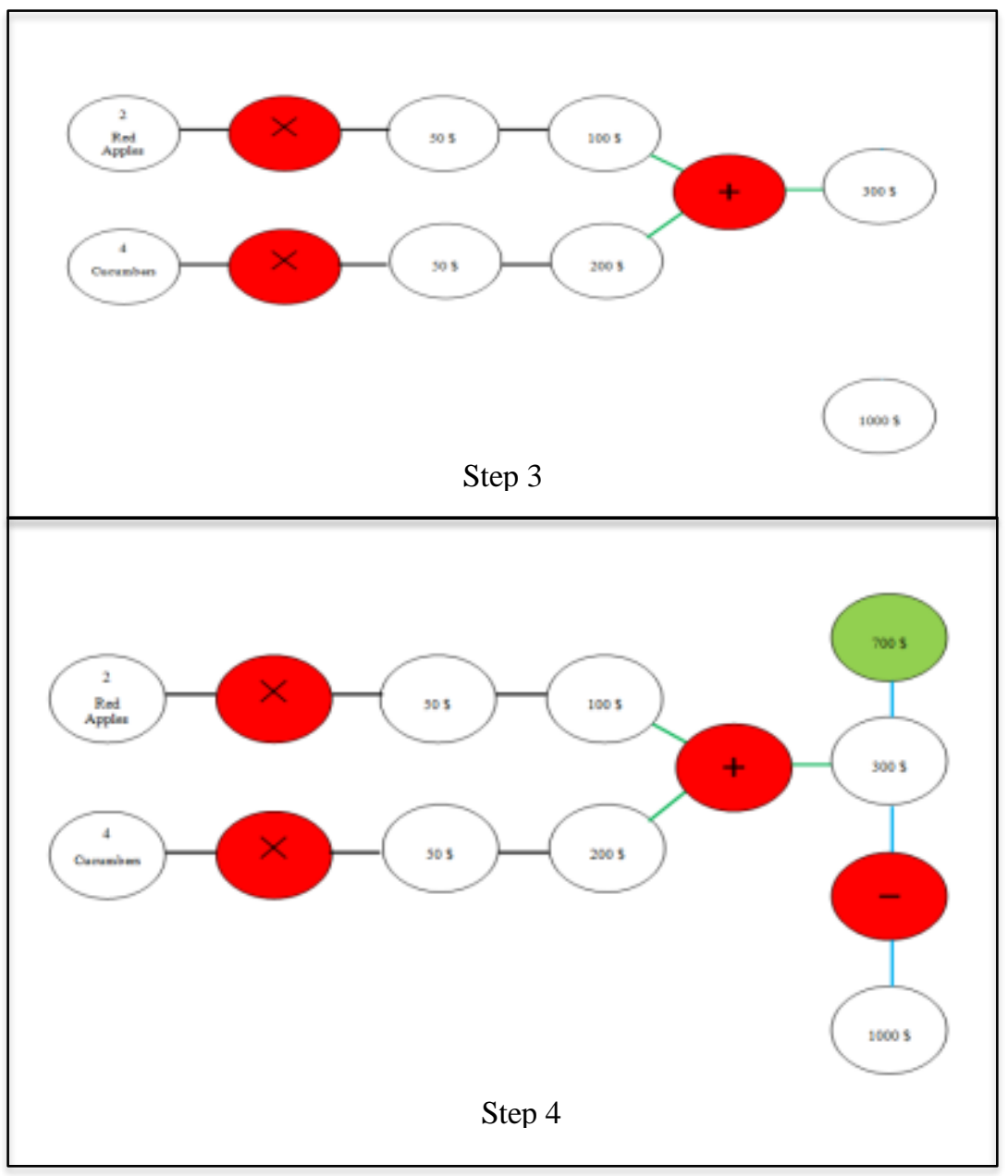

Figure 3. A nonlinear PP

It is important that lines among circles of \$100 and \$200 have a different color than the one from the multiplication operator. Different color (red lines) can contribute to find sub and main paths, helping differentiate them from other paths and each other. At the fourth step, student must find a reminder amount or, the main aim for this WP. Here, student must find the 


\section{Amiripour, Dossey \& Shahvarani-New Schema Approach}

final main path illustrated with a different color (blue lines). Now, the student must find the final answer through subtraction. This is why some of these problem cases are so difficult. Suppose a student has completed a PP, the teacher can ask of him/her to interpret the WP through his/her PP. This type of explanation contributes to WPs, to the design of a problem with these information and operation/s, and through modeling efforts causing students think through in such a problem situation. Students can review their work PP through reading the data and operations again.

The following problem, used in the traditional control classrooms, suggests that a student should have to develop a solution this problem, but the authors have not proposed how to structure this pattern.

Problem: Each of three students has two colorful packages of pencils: a package has 6 pencils (package 1), and the other 12 pencils (package 2). Package 1 has 1 yellow pencil and Package 2 has 2 yellow pencils. How many yellow pencils have these three students? (Davoodi et al., 20142015).

The researcher suggests that students attempt a PP structure for their solutions. A student must put circles for main numbers along with words (step 1). Then, as shown, packages 1 and 2 should relate to 6 and 12 pencils respectively without an operator between them in this PP. Some PPs, such as the PP for the pencil problem, some of the circles have no operator between them (see Figure 4; step 1). Step 2 indicates that one yellow pencil and two yellow pencils have relationship to both package 1's and package 2 's circles, respectively. This indicates circles from right hand belong to circles from left hand. Certainly, no operator can be put between these circles. The lines between them are solid black. This line must differ in color from that of other lines. In the third step, a student finds that 1 yellow pencil for each three students will be 3 yellow pencils by using either multiplication or addition separately, and for the rationing of 2 yellow pencils for each of three students will result in 6 yellow pencils.

This can be found either through multiplication or addition separately (see Figure 4; step 3). This PP has used a multiplication operator. Lines among them are red. Returning to read the original problem, the student finds the problem asked that the student must find the overall total number of yellow pencils. Thus, other operator must add the subtotals found in the two linear sub-PPs. 


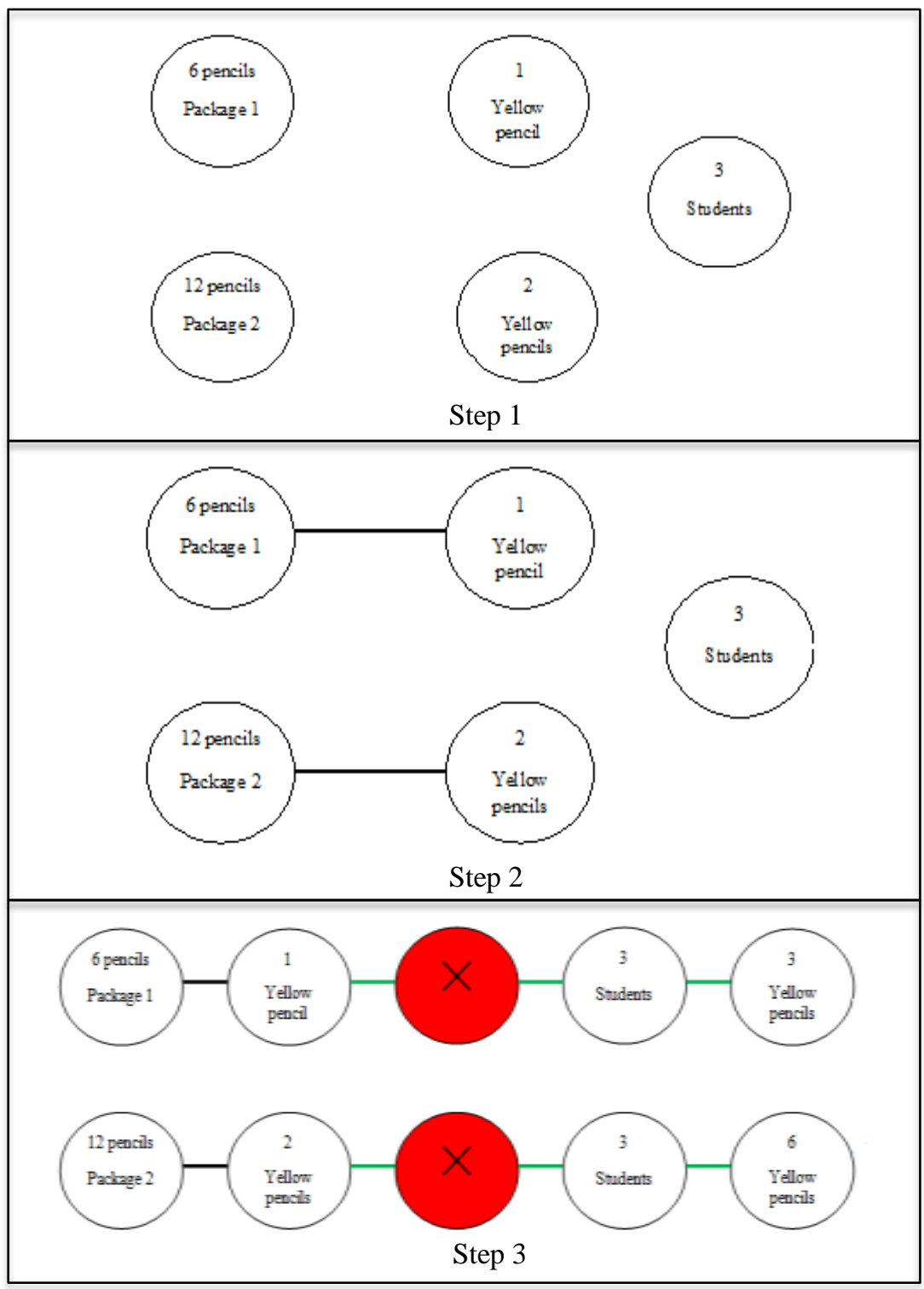

Figure 4. An open nonlinear PP 


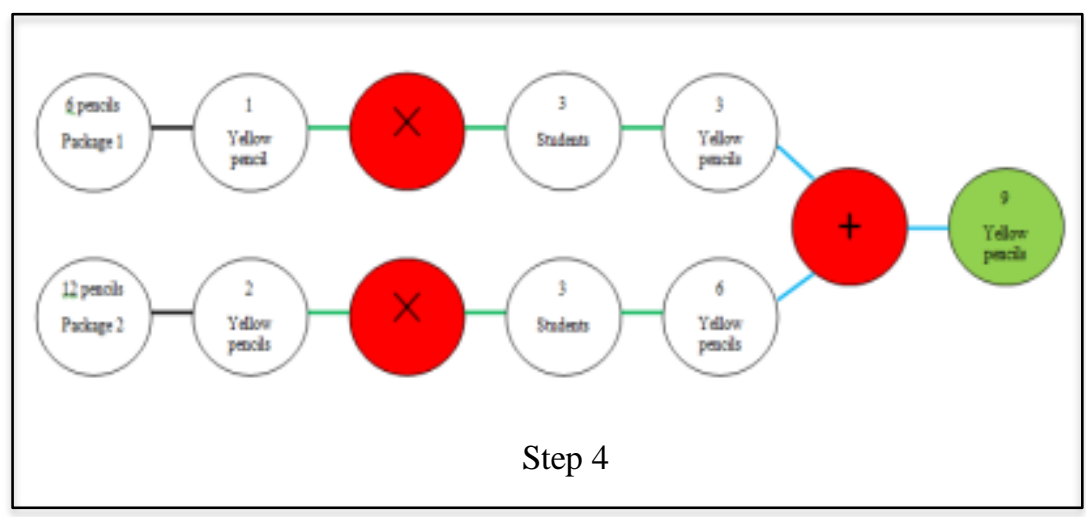

Figure 4. An open nonlinear PP

The subtotals in the two final circles must be added through an addition operator (see Figure 4; step 4) with the other ways/lines (blue lines). This connection of the two linear PPs converts the model into the final nonlinear PP. For steps 1 to 3 the PPs developed were linear, but at fourth step, PP model has converted to that of a nonlinear PP. It is obvious that PPs can be linear in their first steps, but then, the PPs can change to nonlinear PPs. In addition, a special state is observed that there is not any operator between the circles in the first step in above problem.

The researcher has found that PPs can 'closed and open' in addition to having underlying linear or nonlinear models. Many PPs are closed and many are open. Almost all PPs in an Iranian math book are open. Students can observe 'open PPs' often. 'Closed PPs' are special state of PPs that all circles have relationship each other. All previously cited PPs were open PPs. In closed PPs, it seems that all refer to their first circle/s. The colorful lines contribute to determining the main way. A 'closed PPs' is like a circle. Examining these circles, a student can return to the first steps or sometimes a student can propose an 'open PPs' at first steps then develop them to the final steps to complete the whole closure of the closed PP. Closed PPs occur in nonlinear PPs category. It seems that closed PPs are more difficult for students who are categorized as being at-risk students. This problem is a 'closed nonlinear PP': 


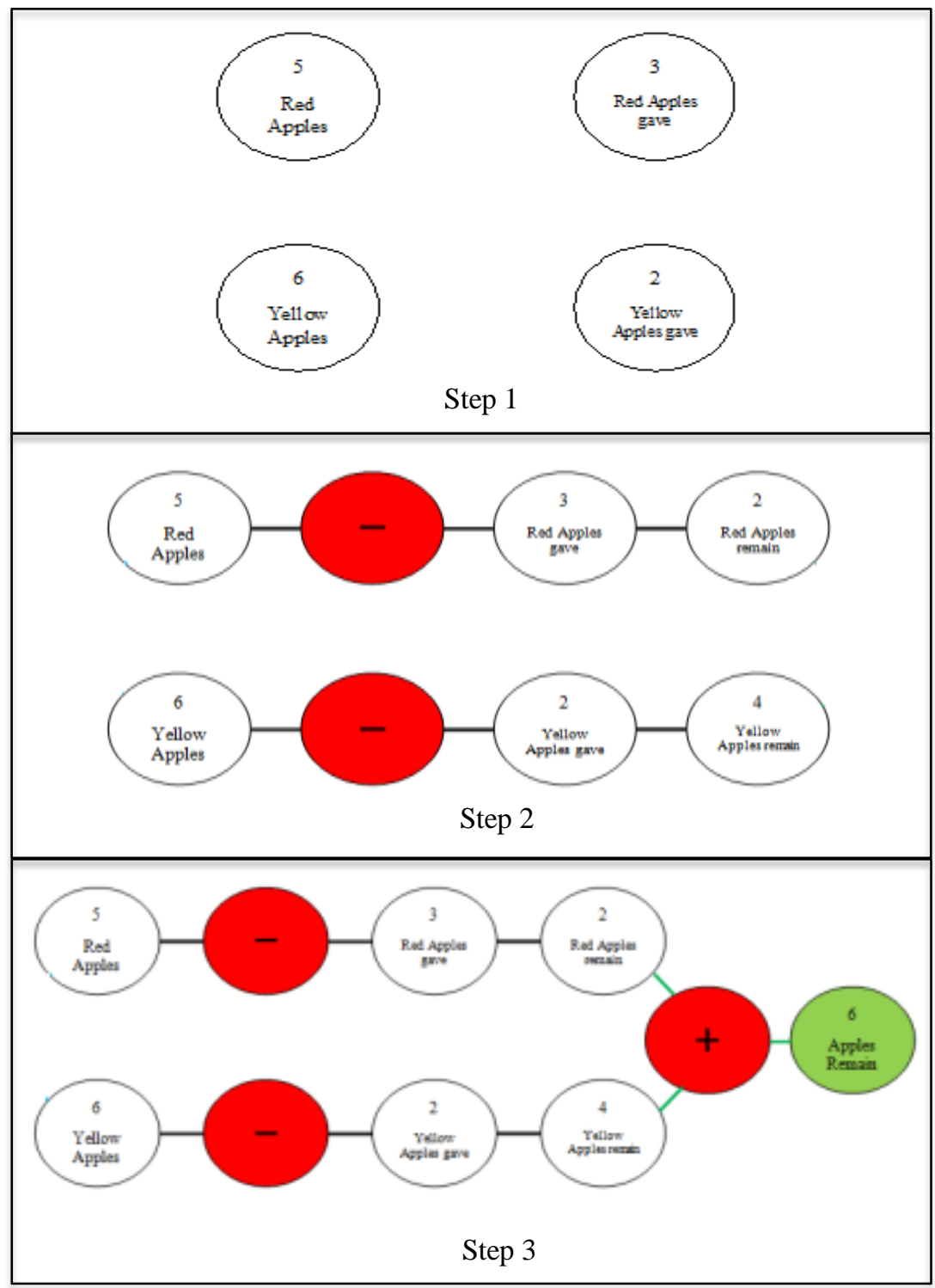

Figure 5. A closed non-linear PP 


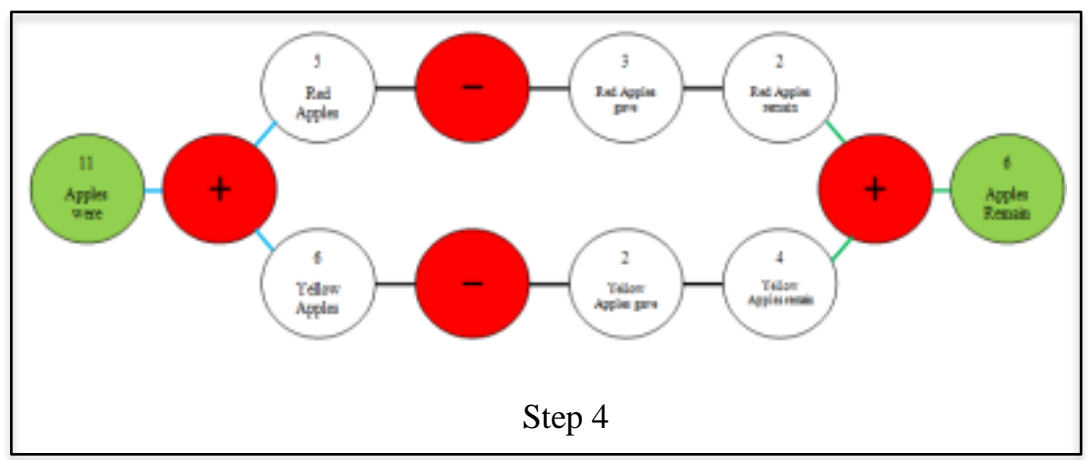

Figure 5. A closed non-linear PP

Problem: John has 5 red apples and Mary has 6 yellow apples too. John gives 3 red apples to his mum, and Mary gives 2 yellow apples to her friend. How many apples do they have now together? How many apples did John and Mary have already together?

In problem, two questions are asked of the students that require the construction of a special PP. At first step, a student main writes numbers along with words for both John and Mary and places them in separate rows. Since the first question following step 1 remains, students must find the number of apples remaining for each of Mary and John separately through red lines and the subtraction operator (Step 2). For the third step, students must response to first question. Thus, the number of apples that remain together must be found by adding through an addition operator with the other lines (blue line). This results in the PP shown. Here, students encounter an 'open-nonlinear PP' (Step 3). Since students still must respond to the final question about the total number of apples John and Mary had at the beginning, the second question from problem.

So, students must return to the first circles and lines. The circles for the 5 and 6 apples for John and Mary, respectively, must be added to the response of the second question, that is, 11 apples in all. Another way to respond would be to draw with another other color (green color) (see step 4). As it is obvious from Step 4, there is not any distance between the two lines. All lines are continuous. There are three ways to show the response in this PP. It seems that there is a relationship between the first circle (11 apples) to final circle (6 apples). Closed nonlinear/linear PPs can often 
indicate a rational relationship existing among the information. This is a difference between a closed PP and an open PP. In open PP (linear/nonlinear), the WPs often follows a unique question but for almost all closed PPs (linear/nonlinear) this does not occur. Closed PPs have many lines and there is a main solution goal tying the first way (circle) and final way showing the total in the right-hand circle in Step 4. In addition, closed PPs are unique as open PPs. PPs must be drawn about special principles governing either linear PPs or nonlinear PPs. As it is shown, all circles written/drawn on left hand and operator's circles must be put among data's circles so that they direct the calculation of how the students $\mathrm{add} /$ subtract/multiple/divide numbers.

\section{Findings}

This section reviews the data outlining the model, data, and demographic data related underpinning the hypothesis that at-risk students taught WPs through the PP approach in the experimental sections will perform statistically significantly better on the posttest than students taught via traditional teacher led instruction in the control sections. While the entire study involved other questions, covered in additional papers, this paper focuses on the major hypothesis: The post-test performance of at-risk students taught by the PP approach differs statistically $(p<0.05)$ from the posttest performance of students taught by the traditional method.

The test data was analyzed by grade levels of the students involved in the experiment due to the differences in the content on the pre- and posttests for students in the two levels: grade 2 and grade 3 . Changes were made in the methods of data analysis because of differences in the numbers of students in the second and third grade experimental samples and others from differences in the variability within in these groups themselves.

Note that there were 35 students in grade 2 and 65 students in grade 3. These numbers resulted from the distribution of at-risk students meeting the criteria of having mathematical learning difficulties and having been retained in grade at least once in kindergarten through grade 3.

The average age of students in the control sections was between 9 and 10 the Society for Protecting the Rights of the Child (Naser Khosrow \& Shosh Houses) and the Association of Protection of Children Labor (Molavi 
\& Khavarn Houses) this average age was between 9 and 11 years of age. Table 2 displays the distribution of the students by gender to the experimental and control groups by grades. Here we see a more disparate assignment of students to experimental and control group membership by the random sampling process used. This is especially seen in the female assignments in grade 2 .

Table 2.

Number of subjects by gender in grade level and in treatment groups

\begin{tabular}{lcccc}
\hline & \multicolumn{2}{c}{ Grade 2 } & \multicolumn{2}{c}{ Grade 3 } \\
\cline { 2 - 5 } & $\begin{array}{l}\text { Experimental } \\
\text { Group }\end{array}$ & Control & Experimental & Control \\
Group & Group & Group \\
\hline Male & 12 & 10 & 14 & 17 \\
Female & 3 & 10 & 21 & 13 \\
Total & 15 & 20 & 35 & 30 \\
\hline
\end{tabular}

Table 3 allows the comparison of students on the pretest and posttest by control and experimental groups by total population. Striking in this data are the similarities of the two groups on the pretests, but their vast differences in their performance on the posttests.

Table 3.

Pretest and posttest score statistics for control and experiment groups

\begin{tabular}{lcccc}
\hline & \multicolumn{2}{c}{ Control Group } & \multicolumn{2}{c}{ Experimental Group } \\
\cline { 2 - 5 } & Pretest & Posttest & Pretest & Posttest \\
\hline $\mathrm{N}$ & 50 & 50 & 50 & 50 \\
Mean & 6.56 & 6.40 & 5.84 & 15.68 \\
Median & 6.00 & 7.00 & 6.00 & 17.00 \\
Mode & 6 & 6 & 5 & 19 \\
Std. Deviation & 1.91 & 2.61 & 2.58 & 3.67 \\
\hline
\end{tabular}

Table 4 allows the reader to examine the performance data further by partitioned further into grade level performance. Here one can detect grade specific differences in the performance between pretest and posttest for grade 2 and grade 3 students. While the tests at both grade levels had possible scores from 0 to 20 points, the following analyses provide separate 
discussions of the control and experimental groups by grade levels, as the combination of their data for analysis would be open to validity challenges because of the differing content tested at the two grade levels. One should also note grade 2 experimental students started below the grade 2 control students but finished considerable higher than them.

Table 4.

Pretest and posttest scores by grades for experimental and control groups

\begin{tabular}{lcccccccc}
\hline \multirow{2}{*}{ By Test } & \multicolumn{3}{c}{ Control Group } & \multicolumn{3}{c}{ Experimental Group } \\
\cline { 2 - 8 } & \multicolumn{2}{c}{ Pretest } & \multicolumn{2}{c}{ Posttest } & \multicolumn{2}{c}{ Pretest } & \multicolumn{2}{c}{ Posttest } \\
\hline By Grade & Second & Third & Second & Third & Second & Third & Second & Third \\
\hline N & 20 & 30 & 20 & 30 & 15 & 35 & 15 & 35 \\
Mean & 6.40 & 6.73 & 5.35 & 7.10 & 6.20 & 5.68 & 15.20 & 15.91 \\
Median & 6.00 & 7.00 & 6.00 & 7.00 & 6.00 & 6.00 & 17.00 & 17.00 \\
Mode & 6 & 6 & 2 & 10 & 6 & 5 & 19 & 18 \\
Std. Dev. & 1.95 & 1.99 & 2.68 & 2.36 & 3.02 & 2.39 & 4.50 & 3.33 \\
\hline
\end{tabular}

The hypothesis states that: The post-test performance of at-risk students taught by the PP approach differs statistically $(p<0.05)$ from the posttest performance of students taught by the traditional method. In the following pages, we will investigate whether there is evidence that allows one to say that chances are that students exposed to the PP approach perform better than their peers in the control group at the $p<0.05$ level.

Before testing groups by performance on their respective pretests and posttests, it necessary to check to assure that the data for each approach is normally distributed, as this is a basic assumption of the $t$-test planned for use. The test results using the Kolmogorov-Smirnov test for the normal distribution of responses in the data for pretests from the control and from the experimental groups by grade 2 and grade 3 levels returned mixed results. The results showed that the data testing normality for both control and experimental classes in grade 2 pretest and posttest classes and in grade 3 pretest classes satisfied the normality criterion $(p>0.05)$. However, while the data for the grade 3 control group satisfied the normality criterion, the data for the grade 3 experimental group for posttest were not normally distributed $(p<0.05)$. Thus, the parametric test, the Independent Samples $t$-Test, is chosen to test for differences in the pretest performance of all 


\section{Amiripour, Dossey \& Shahvarani-New Schema Approach}

grade 2 and the grade 3 pretests. The nonparametric test, the Mann-Whitney $\mathrm{U}$ Test, is used for the posttests of the grade 3 data, as it does not require the normality of the underlying data.

The use of the Independent Samples t-test requires that the data sets being contrasted have equal variances. This was done with the Levene test and in cases for the grade 2 tests, experimental and control and for the grade 3 pretests experimental and control, the criterion for the equality of variances was satisfied. Hence, the analysis continued with the testing of the equality of the pretest and posttest means for both grade 2 pre-test and post-test means for control and experimental groups and for the grade 2 pretest and posttest mean for control and experimental groups. Hence, one can continue to the Independent $t$-test for the posttest means of the two grades 2 groups. Table 5 shows that at the grade 2 level, the results showed that a significant difference ( $p$ asymptotically equal to 0.000 ) existed in the means of the grade 2 posttest scores, where there was no significant difference in the means of the pretest scores between the groups. In fact, there was a lower mean at for the experimental group at the pretest time. Hence, the grade 2 experimental group had a lower mean at the pretest time and a score significantly higher than the control group at posttest time. Thus, for grade 2 students, the PP approach was significantly better than the traditional approach in teaching students WPs techniques.

Table 5.

Independent samples T-test for posttests of grade 2

\begin{tabular}{|c|c|c|c|c|c|c|c|}
\hline & \multirow[t]{2}{*}{$F$} & \multirow[t]{2}{*}{ Sig. } & \multirow[t]{2}{*}{$t$} & \multirow[t]{2}{*}{$\mathrm{df}$} & \multirow[t]{2}{*}{$\begin{array}{c}\text { Mean } \\
\text { Difference }\end{array}$} & \multicolumn{2}{|c|}{$\begin{array}{l}\text { 95\% Confidence } \\
\text { Interval of the } \\
\text { Difference }\end{array}$} \\
\hline & & & & & & Lower & Upper \\
\hline $\begin{array}{l}\text { Equal } \\
\text { variances } \\
\text { assumed }\end{array}$ & 6.20 & 0.17 & $-8.07 *$ & 33 & -9.85 & -12.33 & -7.36 \\
\hline $\begin{array}{l}\text { Equal } \\
\text { variances } \\
\text { not } \\
\text { assumed }\end{array}$ & & & & & -9.85 & -12.56 & -7.13 \\
\hline
\end{tabular}

Note: $* \mathrm{p}<.05$ 
To complete the analysis, we turn to a non-parametric Mann-Whitney U test for examining the difference of means for the posttests at the grade 3 level. The difference of the control and experimental results for grade 3 at the posttest level was significant. The results of the Mann-Whitney U-test showed that comparison of the ranks for the two grades 3 samples (Table 6) to be statistically significant favoring the experimental group ( $p$ asymptotically equivalent to 0.000 ) in Table 7 . We must reject the null hypothesis and accept the alternative hypothesis give the resulting $p$-value approaching 0.000 , a value clearly satisfying the $(p<0.05)$ criterion. One then rejects the null hypothesis of no difference in performance and accepts the alternative hypothesis that students in the experimental group performed significant better in the experimental group at the grade 3 level.

Table 6.

Calculated ranks for the posttests of the grade 3

\begin{tabular}{cccc}
\hline Code & $\mathrm{N}$ & Mean rank & Sum of ranks \\
\hline $\begin{array}{c}\text { Control } \\
\text { group }\end{array}$ & 30 & 16.60 & 498.00 \\
$\begin{array}{c}\text { Experiment } \\
\text { group }\end{array}$ & 35 & 47.06 & 1647.00 \\
Total & 65 & & \\
\hline
\end{tabular}

Combining this result with the similar finding at the grade 2 level, we conclude that the use of the PP approach to the teaching of WPs was significantly better than the traditional approach in the learning of WPs.

Table 7.

Mann-Whitney test for posttest of grade 3

\begin{tabular}{ll}
\hline Statistics & Posttests \\
\hline Mann-Whitney U & 33.00 \\
Wilcoxon W & 498.00 \\
$\mathrm{Z}$ & $-6.50^{*}$ \\
\hline
\end{tabular}

Note: *p<.05 


\section{Conclusion}

In the present research, the PP approach is proposed as a strategy for WPs. Since many students cannot solve complex WPs, it seemed that teachers should introduce a new and efficient strategy for WPs as an educational intervention. The PPs approach was developed and after revisions following pilot testing, the research team found evidence for introduced PPs for atrisk students in the experimental study described. At-risk students were chosen from among students having mathematical difficulties and who had also been retained in grade in at least one year. Further, they did not pass the school's final mathematics examination in the previous year. These students' work with WPs was characterized by repeated mistakes in WPs.

In the first instructional sessions with PPs in the experimental classes, at-risk students practiced building models for linear PPs through colorful colored clay and pipe cleaner models. The researcher introduced the PPs approach by having the students work in small groups to model linear problems. At first, at-risk students were unable to design PPs correctly, voicing a dislike the new PP approach. Students could not think through the identification of the main structure of the natural number WPs. The researcher then asked them to find the main information at first. Then, the students were directed to examine the relationship between the known data and unknown in the WPs. This was followed by finding and relating a main operation $(+,-, \times, \div)$ to the linear PPs models. Conversations between the researcher and at-risk students often contributed to students' increased understanding and improvement in their designs for PPs. After one month, they could identify and design the main path between the main information (numbers and unknowns) and find the operation related to the problems presented. Then, a second step was to solidify students' capability to find the main path among data and unknowns, operation/s, and the final answer. Many students found that smaller numbers could not be used as subtrahends in subtraction problems. The relational places that number(s) take in finding the main path to finding a final answer began to develop.

After the second month, at-risk students had improved their linear PPs from the first month level, so they began working on nonlinear PPs. This shift was very difficult for them. For nonlinear WPs, at-risk students faced many challenges. When the number of operations was greater than the one, students had extreme difficulty working with the related nonlinear PPs. 
This change created a greater information-processing load for at-risk students as this also increased the number of data points and unknowns involved in the WPs. Students discovered that the separation of main information was possible through viewing individual PPs as part of building a model for the more complex nonlinear problems. This allowed at-risk students to handle the nonlinear settings. As students worked with both linear and nonlinear PPs, problems were presented based in stories (dramas) of a family engaged in routine problem situations requiring mathematical-based solutions. At-risk students were thus engaged in settings using "age, money, time, categorize, distance, length, and weight" along with the four main operations in PPs. The researcher had to supply more help in the first steps of structuring and answering nonlinear PPs. At this point, the researcher first asked and modeled answering the questions to be asked. It was here that the researcher found that at-risk students had to use different colors for modeling the data and pipe cleaner for the two embedded PPs. This step of using use different colors for the embedded linear PPs found in nonlinear PPs assisted at-risk students in finding the separate embedded paths the first information, its answer, and the movement to the final solution. During the third month, many of the at-risk students began to design open nonlinear PPs and extended their understandings to closed nonlinear PPs. Closed nonlinear PPs were very difficult for at-risk students, particularly second graders. Conversations between the researcher and experimental sessions students took place during the three months of the experimental treatment, as well as pretest, four intersession exams, and a posttest. In the control groups students' classroom teachers proceeded as normal with texts normally found in the Iranian school mathematics curriculum and taught students in the control sections in the participating schools the solution of WPs as traditionally done. The only difference for them was the administration of the tests associated with the experiment.

In the control group, the researcher worked with at-risk students under the same conditions as with the experiment group except for teaching from the adopted mathematics text, which was the same text in all classes involved, differing only by the grade level intended. The PP approach was not used in the control sections. One classroom assessment difference was asking control students to draw a representation of problems which was not 


\section{Amiripour, Dossey \& Shahvarani-New Schema Approach}

a textbook-based instructional method. However, the results showed this did not have a significant effect on control students versus experimental students. However, students in the experiment groups could propose PPs correctively and draw a design or schema that led to finding the main path/s and final solution. As all the at-risk students have essentially the same surrounding conditions regarding social, cultural, and financial situations, as well as all students were workers outside of class with hard working conditions, it appears that the PP approach is a promising approach for use in classes with at-risk students.

\section{References}

Carpenter, T. P. \& Moser, J. M., (1983). The acquisition of addition and subtraction concepts. In R. Lesh \& M. Landau (Eds.), Acquisition of mathematical concepts and processes (pp. 7-44). New York: Academic Press.

Case, L. P, Harris K. R, \& Graham S. (1992). Improving the mathematical problem solving skills of students with learning disabilities: Selfregulated strategy development. Journal of Special Education, 26, 119. doi: $10.1177 / 002246699202600101$

Claessens, A., Duncan, G. J., \& Engel, M. (2009). Kindergarten skills and fifth-grade achievement: Evidence from the ECLS-K. Economics of Education Review, 28(4), 415-427. doi:http://journals.sagepub.com/doi/10.1177/002246699202600101

Cronbach, L. J. (1951). Coefficient alpha and the internal structure of tests. Psychometrika, 22(3), 297-33. Doi: 10.1007/BF02310555

Davoodi, KH., Rastegar, A., \& Alamiyan, V. (2014-2015). $3^{\text {rd }}$ Math book. Tehran: Islamic Republic of Iran Education.

Duncan, G. J., Dowsett, C. J., Classens, A., Magnuson, K., Huston, A. C., Klebanov, P., \& Japel, C. (2007). School readiness and later achievement. Developmental Psychology, 43(6), 1428-1446. doi:10.1037/0012-1649.43.6.1428.

Duncan, G. J., \& Magnuson, K. A. (2011). The nature and impact of achievement skills, attention skills, and behavior problems. In G. J. Duncan \& R. J. Murnane (Eds.), Whither opportunity? Rising inequality, schools, and children's life chances (pp. 47-69). New York: Russell Sage Foundation. 
Fuchs, L.S., Fuchs, D., Finelli, R., Courey, S.J., \& Hamlett, C.L. (2004). Expanding schema-based transfer instruction to help third graders solve real-life mathematical problems. American Educational Research Journal, 41, 419-445. doi: 10.3102/00028312041002419 Fuchs, L. S., Geary, D. C., Compton, D. L., Fuchs, D., Schatschneider, C., Hamlett, C. L., \& Changas, P. (2013). Effects of first-grade number knowledge tutoring with contrasting forms of practice. Journal of Educational Psychology, 105(1), 58-77. doi:10.1037/a0030127.

Garcia, A. I., Jimenez, J. E. \& Hess, S. (2006). Solving arithmetic word problems: An analysis of classification as a function of difficulty in children with and without arithmetic learning difficulties. Journal of Learning Disabilities, 39(3), 270-281. doi:

10.1177/00222194060390030601

Jitendra, A., \& Xin, Y.P., (1997). Mathematical word problem-solving instruction for students with mild disabilities and students at risk for math failure: A research synthesis. The Journal of Special Education, 30, 412-438. doi: 10.1177/002246699703000404

Jitendra, A. (2002). Teaching students' math problem solving through graphic representations. Teaching Exceptional Children, 34(4), 3438. doi: 10.1177/004005990203400405

Jitendra, A.K., \& Hoff, K. (1996). The effects of schema-based instruction on mathematical word-problem-solving performance of students with learning disabilities. Journal of Learning Disabilities, 29, 422-431. [PubMed: 8763557]. doi: 10.1177/002221949602900410

Jordan, N. C. (2007). The need for number sense. Educational Leadership, 65(2), 63-66.

Jordan, N. C., Kaplan, D., Ola'h, L. N., \& Locuniak, M. N. (2006). Number sense growth in kindergarten: A longitudinal investigation of children at risk for mathematics difficulties. Child Development, 77(1), 153-175. doi: 10.1111/j.1467-8624.2006.00862.x

Jordan, N.C., Kaplan, D., Ramineni, C., \& Locuniak. M.N. (2009). Early math matters: Kindergarten number competence and later mathematics outcomes. Developmental Psychology, 45(3), 850-867. doi: $10.1037 /$ a0014939

Kroesbergen, E. H., \& Van Luit, J. E. H. (2003). Mathematical interventions for children with special educational needs. Remedial 
254 Amiripour, Dossey \& Shahvarani - New Schema Approach

and Special Education, 24, 97-114. doi:

10.1177/07419325030240020501

McCann, R. A., \& Austin, S. (1988). At-risk youth: Definitions, dimensions and relationships. Philadelphia: Research for Better Schools Inc. (ERIC Document Reproduction Service, No. 307/359).

Mastropieri, M. A, Scruggs, T. E, Shiah, R. (1997). Can computers teach problem solving strategies to students with mild mental retardation? Remedial and Special Education, 18, 157-165. doi:

10.1177/074193259701800304

Miller, S.P., \& Mercer, C.D. (1993). Using data to learn about concrete semi concrete abstract instruction for students with math disabilities. Learning Disabilities Research and Practice, 8, 89-96. doi: 10.1111/1540-5826.00068

Montague, M., \& Applegate, B., (2000). Middle school students' perceptions, persistence, and performance in mathematical problem solving. Learning Disability Quarterly, 23, 215-227. doi: $10.2307 / 1511165$

Morgan, P. L., Farkas, G., \& Wu, Q. (2009). Five-year growth trajectories of kindergarten children with learning difficulties in mathematics. Journal of Learning Disabilities, 42(4), 306-321. doi: $10.1177 / 0022219408331037$

National Governors Association Center for Best Practices \& Council of Chief State School Officers. (2010). Common Core State Standards for Mathematics. Washington, DC: Author. Retrieved from http://www.corestandards.org/assets/CCSSI_Math\%20Standards.pdf.

National Mathematics Advisory Panel. (2008). Foundations for success: The final report of the National Mathematics Advisory Panel (ED 00424P). Washington, DC: U.S. Department of Education.

National Research Council. (2009). Mathematics learning in early childhood: Paths toward excellence and equity. Washington, DC: National Academies Press.

OECD (2016), Equations and Inequalities: Making Mathematics Accessible to All, PISA, Paris: OECD Publishing. doi: 10.1787/9789264258495en

Powell, S. (2011). Solving word problems using schemas: A review of the literature. Learning Disabilities Research \& Practice, 26, 94-108. doi: 10.1111/j.1540-5826.2011.00329.x 
Robinson, C. S., Menchetti, B. M., \& Torgesen, J. K. (2002). Toward a two-factor theory of one type of mathematics disabilities. Learning Disabilities Research \& Practice, 17(2), 81-89. doi:10.1111/15405826.00035.

Schiff, R., Bauminger, N., \& Toledo, I. (2009). Analogical problem solving in children with verbal and nonverbal learning disabilities. Journal of Learning Disabilities, 42(1), 3-13. doi: 10.1177/0022219408326213 Starkey, P., Klein, A., \& Wakeley, P. (2004). Enhancing young children's mathematical knowledge through a pre-kindergarten mathematics intervention. Early Childhood Research Quarterly, 19(1), 99-120. doi:10.1016/j.ecresq.2004.01.002.

Van Garderen, D. (2007). Teaching students with LD to use diagrams to solve mathematical word problems. Journal of Learning Disabilities, 40, (540-553). doi: 10.1177/00222194070400060501

Parvaneh Amiripour is $\mathrm{PhD}$ student in the Department of Mathematics, Science and Research Branch, Islamic Azad University, Tehran, Iran.

John A. Dossey is emeritus professor in the Department of Mathematics, at Illinois State University, USA.

Ahmad Shahvarani is associated professor in the Department of Mathematics, Science and Research Branch, Islamic Azad University, Tehran, Iran.

Contact Address: Direct correspondence concerning this article, should be addressed to the author. Postal address: 65111 East Crystal Ridge, Tucson, AZ, 85739, USA. Email: jdossey@illinoisstate.edu , jdossey44@gmail.com 